\title{
El Adentro y Afuera de la Exclusión Social. Estudio Cualitativo de Cuatro Barrios Excluidos
}

\section{The inside and outside of Social Exclusion. Qualitative study of four Neighborhoods Excluded}

\author{
Teresa Ropert Lackington (1), Lucaz Gonzalez Espinoza² (), \\ Dariela Sharim Kovalskys ${ }^{3}$ (10 y Pablo De Tezanos-Pinto ${ }^{4}$
}

\begin{abstract}
RESUMEN
Se presenta un estudio cualitativo llevado a cabo con jóvenes de cuatro barrios excluidos en Santiago de Chile: La Legua, José María Caro, Lo Hermida y Los Robles. El diseño metodológico involucró una diversidad de técnicas de producción de datos que permitieron identificar los relatos subjetivos de sus habitantes, así como la mirada externa de los barrios. Los resultados sugieren que las percepciones subjetivas (o desde adentro) de los/ as jóvenes de barrios excluidos dan cuenta de que reconocen la desigualdad estructural que los/as aqueja, pero son también críticos de esta lectura, y de los estigmas espaciales que se les imputa (desde fuera), matizando tales clasificaciones con experiencias biográficas asociadas a sentimientos positivos en sus barrios. El artículo concluye que el concepto de barrio excluido necesita de la articulación dialéctica entre subjetividad y sociedad, o entre miradas desde adentro y afuera, para abrirse a nuevos procesos de cambio social.
\end{abstract}

Palabras clave: Barrios excluidos, mirada externa, experiencia subjetiva, segregación, exclusión social.

\begin{abstract}
This paper presents a qualitative study carried out with young people from four excluded neighborhoods in Santiago de Chile: La Legua, José María Caro, Lo Hermida and Los Robles. The methodological design involved a variety of data production techniques, allowing us to identify the subjective narratives of their inhabitants, as well as the external perceptions of the neighborhoods. Results suggest that the subjective (or 'from inside') perceptions of young people from excluded neighborhoods incorporate the structural inequality that afflicts them, but they are also critical of this reading, as well as the spatial stigmas imputed to them, qualifying such classifications with biographical experiences associated with positive feelings in their neighborhoods. The paper concludes that the concept of excluded neighborhood requires a dialectic articulation between subjectivity and society, or between an internal and external outlook, in order to open new directions for social change.
\end{abstract}

Keywords: Excluded neighborhoods, external glance, subjective experience, segregation, social exclusion

Pontificia Universidad Católica de Chile, Correo Institucional: mtropert@uc.cl

Universidad Alberto Hurtado, Correo Institucional: LucazGE@hotmail.com

Pontificia Universidad Católica de Chile, Correo Institucional: dsharim@uc.cl

Pontificia Universidad Católica de Chile, Correo Institucional: pablo.detezanospinto@uai.cl 
Durante las últimas décadas, la mayoría de las grandes ciudades del mundo han sido testigo de importantes transformaciones en la organización social y urbana del territorio. Si bien hay que evitar caer en comparaciones generalistas que tiendan a obviar diferencias entre ciudades alrededor del mundo, cierto es que las sociedades contemporáneas han visto el crecimiento progresivo de metrópolis dualizadas, donde las desigualdades históricas de la ciudad se arraigan y acumulan en territorios socio-urbanos que contrastan opulencia y precariedad (Fuentes \& Link, 2014; Wacquant, 2007, 2001). Este fenómeno de polarización urbana ha venido asociado a una creciente preocupación respecto de la situación de aquellos y aquellas que se emplazan en territorios de acumulación de desventajas, lo que resulta particularmente relevante en Latinoamérica, por sus elevados niveles de desigualdad (e.g. CEPAL, 2018; Ziccardi, 2008; Prevot-Shapira, 2005; Mingione \& Oberti, 2003; Mingione, 1997).

Además, la desigualdad en los países latinoamericanos se ha acrecentado en las últimas décadas por efecto de la implantación de modelos económicos neoliberales, que priorizan las lógicas de mercado en el acceso a vivienda, por sobre los derechos sociales (Fuentes \& Link, 2014; Fraile, 2009; Ziccardi, 2008). Además, uno de los grupos más desfavorecidos con las transformaciones de la economía y la globalización son justamente aquellos que se encuentran relegados en contextos barriales estigmatizados, que se erigen como territorios societales extremos, donde las instituciones democráticas tradicionales tienden a fallar (Ruiz Flores, 2012; Kruijt \& Konings, 2007), donde tienden a concentrarse problemáticas de violencia y criminalidad (Tocornal, Tapia \& Carvajal, 2014) y donde parece producirse una cierta condena al lugar, en la medida en que no se cuenta con los recursos de acceso completo a las nuevas redes globales, en un mundo cada vez más móvil e interconectado (Bauman, 2007).

En el caso de Chile, a pesar de políticas públicas que han hecho numerosos esfuerzos por reducir la pobreza, posicionando sus niveles por debajo de la región latinoamericana en los últimos veinte años, los resultados no son positivos y el país sigue posicionándose como uno de los más desiguales del mundo, en estándares OCDE (Brandt, 2012). A su vez, investigaciones más recientes han planteado que la vertiginosa transformación de Santiago en una gran metrópolis urbana - siguiendo la tendencia internacional- ha venido asociada a una re-jerarquización socio-espacial, trayendo nuevas formas de estratificación social (De Mattos, Fuentes \& Link, 2014) y contribuyendo a generar en Santiago una fuerte segregación (e.g. Sabatini, Rasse, Cáceres, Robles \& Trebilcock, 2017; Agostini, Hojman, Román \& Valenzuela, 2016; CNDU, 2015; Fuentes \& Link, 2014), la que es entendida como una falta de interacción entre grupos sociales distintos, por su grado de separación espacial dentro de la ciudad, la que conlleva a una comunidad fragmentada y desigual (Agostini, et. al., 2016). Es más, recientes estudios respecto de la segregación socioespacial en Santiago han mostrado, a través de la construcción de tipologías socioespaciales, la estructura fuertemente jerárquica y polarizada de la ciudad que parece avanzar hacia la disociación de grupos distribuidos homogéneamente en el territorio según sus perfiles sociolaborales (Link, Valenzuela \& Fuentes, 2015).

Por otra parte, desde los inicios del siglo XXI se ha visto un creciente interés no sólo por intervenir, sino también por estudiar las dinámicas sociales que se producen dentro de los territorios segregados de nuestro país. El barrio excluido, retomando el concepto que utiliza Ruiz Flores (2012) para enfatizar su relación con la macroestructura social, refiere a un lugar donde la democracia falla y donde se produce una falta de reconocimiento a los derechos humanos y políticos 
fundamentales. Otras autoras han definido estos nodos urbanos principalmente como espacios caracterizados tanto por sus problemáticas psicosociales (violencia urbana, narcotráfico, hacinamiento, entre otras), como por la sobreintervención que reciben por parte del Estado, así como por sus significados asociados a la marginalidad, la exclusión y el afuera (Reyes, Arensburg \& Poó, 2016). En efecto, el adjetivo de "excluido" resulta particularmente significativo, en la medida en que dentro de estos barrios se construyen:

"vidas que emergen en un contexto que se encuentra saturado de estrategias de dominio y formalización del otro-sujeto y del otro-territorio, usualmente codificados como "marginados" y "excluidos" desde un "afuera" -llámese Estado y/o mercado-, en la medida que con sus acciones no solo interrogan el orden establecido, sino que también lo trastocan". (Reyes, 2016, p.13)

En efecto, muchas investigaciones en barrios excluidos parece focalizarse en cómo el contexto sociopolítico y espacial es (re)sentido subjetivamente por sus habitantes (ver Álvarez \& Cavieres, 2016; Reyes, Arensburg \& Póo; 2016; Rasse, 2015; Ortega, 2014; Ruiz Flores, 2012; Manzano, 2009; Ruiz, 2009), mientras que otras analizan la influencia de los procesos de conformación sociohistóricos del territorio en la constitución social de una ciudad segregada (ver Rivera, 2012; Hidalgo, 2002, 2004; Espinoza, 1998; etc.). Con todo, la revisión de las dinámicas que se dan dentro de los territorios excluidos de Santiago de Chile parece sugerir que la articulación contexto-espacio-subjetividad trae consigo elementos claves para comprender la exclusión socioespacial.

Siguiendo con lo anterior, recientes estudios han mostrado cómo la relación entre los barrios y la estructural macrosocial es en muchos casos conflictiva. Por ejemplo, algunos de estos barrios se han construido desde una experiencia subjetiva de la espera, frente a un Estado que no cumple con la política pública esperada (Álvarez \& Cavieres, 2016), al tiempo en que se configuran como territorios que representan espacios sociales donde la democracia y las instituciones fallan (Ruiz Flores, 2012). A su vez, la concentración de problemáticas de exclusión social en zonas específicas del territorio, que tienden a marcar una fuerte homogeneidad interna, junto con la ausencia de interacción social con otros grupos, explicaría a su vez la concentración de patologías sociales, como la criminalidad, la drogadicción y el desempleo (Fuentes \& Link, 2014).

De esta manera, el espacio del barrio puede provocar profundas contradicciones entre la socialización dentro del barrio y la socialización fuera de él, cuando la primera involucra mecanismos de criminalización y marginalización respecto de la cultura hegemónica (Ortega, 2014). Con todo, un análisis de los mecanismos de interrelación entre el adentro y el afuera - metáfora espacial que alude a la posición del 'desde dónde estamos hablando'- del territorio excluido y segregado, parece ofrecer lineamientos pertinentes para una comprensión novedosa de la exclusión socioespacial. La pregunta que cabe hacerse entonces es: ¿cómo se articula la relación entre las experiencias subjetivas 'desde dentro' del territorio excluido y los discursos sobre los lugares excluidos que provienen 'desde afuera'?

Esta pregunta busca, entre otras cosas, resistir a los mecanismos de invisibilización advertidos por Wacquant (2007), que promueven una comprensión de la exclusión social como un problema ahistórico que no es responsabilidad de nadie. En este sentido, el artículo no consiste en una revisión sistemática de cómo las políticas públicas han operado en los procesos de segregación 
y exclusión social en la ciudad a través de las décadas (ver Hidalgo, 2004, 2002), ni tampoco se centra exclusivamente en las experiencias subjetivas del adentro de estos barrios, sino más bien busca avanzar en una comprensión dialéctica del adentro-afuera que permita discutir el concepto de barrio excluido desde nuevas aristas. En este sentido, retomamos los postulados de Saskia

Sassen (2003) buscando considerar la escala local como protagonista, en el rol de comprender no sólo el proceso de producción de la exclusión barrial, sino también su potencial transformador de la sociedad como un todo. Esto pues, en efecto, la escala urbana o el estudio de los espacios barriales puede ser un objeto de estudio especialmente iluminador de las problemáticas de exclusión social, puesto que en ellos se actualizan cotidianamente tanto los procesos de orden macrosocial vinculados a la desigualdad, la pobreza y la discriminación, como los procesos sociales interaccionales que se desprenden y los contestan (Mingione \& Oberti, 2003).

En definitiva, el presente artículo busca analizar las experiencias subjetivas que tienen los habitantes jóvenes de los barrios excluidos, desde el interior de sus barrios, contrastándolas con los significados sociales -muchas veces estigmáticos- propios de la exclusión social. Para esto, consideraremos una definición de exclusión social que resalte su carácter dinámico y permita relevar que es resultado de la interacción entre las acciones humanas y las fuerzas sociales estructurales (Giddens, 2009), derribando concepciones unilaterales que pongan al individuo como receptor pasivo de sus condiciones estructurales desiguales (Lunecke, Munizaga \& Ruiz, 2009). Así, la tesis central que guía este trabajo es que un análisis desde el adentro, es decir, desde las experiencias subjetivas de los habitantes, permitirá tensionar los discursos del afuera, mediáticos, académicos y/o públicos. Se cree que sólo a través de este proceso, que tensiona discursos sociales desde el adentro, es que se hace posible comprender el fenómeno de la exclusión social como proceso dinámico, que es también producto de fuerzas estructurales y se erige por ende como síntoma de una estructura social que lo produce. Así, nos enfocaremos primero en detallar el diseño metodológico que enmarca el estudio de esta escala local que tensiona procesos desde el adentro y el afuera, para posteriormente detallar algunos aspectos de esta tensión, revisando algunos discursos del afuera sobre barrios excluidos así como datos empíricos emergentes desde el adentro del trabajo de campo, realizado en cuatro barrios excluidos dentro del Sistema Urbano Metropolitano de Santiago [SUMS], de acuerdo a la nomenclatura propuesta por De Mattos, Fuentes y Link (2014).

\section{Definiciones metodológicas para el estudio del adentro-afuera}

El marco epistemológico del presente estudio consistió en un diseño cualitativo, de carácter exploratorio-descriptivo. Uno de los supuestos epistemológicos claves tuvo que ver con considerar que el conocimiento social es coproducido en la relación entre investigadores/as y participantes (e.g. Sandoval, 2013; Cornejo, Besoain y Mendoza, 2012; Sisto, 2008; Autor/a, 2001), a la vez que es situado; es decir, se halla siempre anclado a un cuerpo, a un momento histórico y a un determinado lugar (Sandoval, 2013; Haraway, 1988), incluyendo una dimensión performativa en su producción (Denzin, 2001). En este sentido, el proceso de recolección y análisis de datos tuvo el cuidado de pensar el dato como un producto relacional, entre investigadores/as y participantes, por lo que se buscó un análisis que diera sistematicidad a la vez que diálogo y reflexividad colectiva, durante todo el proceso de generación de conocimientos. Para traducir estos postula- 
dos epistemológicos al trabajo en terreno, se llevó a cabo un diseño metodológico que involucró distintas etapas, las que se detallan a continuación.

\section{Selección de barrios}

La primera etapa del diseño consistió en definir lo que se consideraría barrio excluido, por medio de una revisión de la literatura y algunas políticas públicas. Esto derivó en la selección de cuatro barrios, incluyendo una combinación de criterios comunes que permitieran definirlos bajo el nombre de barrios excluidos, y de criterios de variabilidad que favorecieran su comparabilidad analítica (Patton, 2002). Posterior a esta selección, se realizó un trabajo de revisión de titulares de noticias en línea que refirieran a alguno de estos cuatro barrios, con el fin de analizar los significados mediáticos asociados.

Los elementos considerados para establecer comparabilidad entre los barrios fueron: (a) su reciente declaración como zona urbana prioritaria por el Ministerio de Vivienda y Urbanismo [MINVU] (2014-2018), (b) un índice de pobreza comunal elevado, según lo desarrollado por Agostini, Brown \& Góngora, (2008), y (c) el reconocimiento como poblaciones emblemáticas para el desarrollo de la ciudad, especialmente asociadas a una historia política ligada a la lucha obrera y la resistencia de la dictadura ${ }^{1}$ (Álvarez, 2014; Garcés, 2013; Lin Muñoz, 2012; Ruiz Flores, 2012; Ganter, 2010; Parraguez, 2010; Manzano, 2009; Garcés \& Leiva, 2005). Por otra parte, para los criterios de variabilidad se consideraron las siguientes dimensiones: (d) su localización en el sistema urbano metropolitano de Santiago, de acuerdo a la clasificación de De Mattos, Fuentes \& Link (2014), (e) su orientación geográfica, y (f) su presencia en la ejecución de la primera versión del Programa Barrio Seguro (Subsecretaría de Prevención del Delito, 2013). Por último, se consideró también como criterio de variabilidad (g) la experiencia previa del equipo de investigación en cada uno de los barrios. Este último criterio es relevante para considerar la inserción del equipo de investigación en los distintos barrios, y la toma de notas de campo que se presentarán más abajo. Los criterios de selección por barrio se resumen en el Cuadro $N^{\circ} 1$ y su ubicación geográfica se presenta en la Figura $N^{\circ} 1$.

Cuadro $\mathrm{N}^{\circ} 1$

Criterios de selección de barrios excluidos ${ }^{5}$

\begin{tabular}{|l|c|c|c|c|c|c|c|}
\hline \multicolumn{9}{|c|}{ Criterio común } & & Máxima Variabilidad & \\
\hline Comuna & Barrio & $\begin{array}{c}\text { Indice } \\
\text { Pobreza }\end{array}$ & $\begin{array}{c}\text { Zona } \\
\text { Prioritaria }\end{array}$ & $\begin{array}{c}\text { Localización } \\
\text { SUMS }\end{array}$ & Orientación & $\begin{array}{c}\text { Barrio } \\
\text { Seguro }\end{array}$ & $\begin{array}{c}\text { Experiencia } \\
\text { investigadores }\end{array}$ \\
\hline Colina & $\begin{array}{c}\text { Los } \\
\text { Robles }\end{array}$ & 0.306 & Sí & $\begin{array}{c}\text { Fuera mancha } \\
\text { urbana } \\
\text { contigua }\end{array}$ & Norte & No & No \\
\hline $\begin{array}{l}\text { San } \\
\text { Joaquín }\end{array}$ & $\begin{array}{c}\text { La } \\
\text { Legua }\end{array}$ & 0.221 & Sí & $\begin{array}{c}\text { Dentro de A. } \\
\text { Vespucio }\end{array}$ & Centro & Sí & Sí \\
\hline Lo Espejo & $\begin{array}{c}\text { J. M. } \\
\text { Caro }\end{array}$ & 0.229 & Sí & $\begin{array}{c}\text { Dentro de A. } \\
\text { Vespucio }\end{array}$ & Sur-Poniente & Sí & No \\
\hline Peñalolén & $\begin{array}{c}\text { Lo } \\
\text { Hermida }\end{array}$ & 0.239 & Sí & $\begin{array}{c}\text { Fuera de A. } \\
\text { Vespucio }\end{array}$ & Sur-Oriente & No & Sí \\
\hline
\end{tabular}

Fuente: Elaboración propia

\footnotetext{
El caso de Los Robles fue el único que no contó con este respaldo en la revisión bibliográfica, por ser un barrio integrado sólo recientemente a las conceptualizaciones de la ciudad (ver concepto de mancha urbana contigua que incorpora la comuna de Colina, en De Mattos, Fuentes \& Link, 2014), si bien la propia investigación en terreno permitió situar su historia, también ligada con la lucha obrera y la apropiación autónoma del territorio rural por parte de los vecinos, desde mediados del siglo XX (Notas de Campo, Reunión Oficina Municipal de Jóvenes en Colina).
} 
Figura $\mathrm{N}^{\circ} 1$

Ubicación geográfica de comunas seleccionadas en el Gran Santiago.

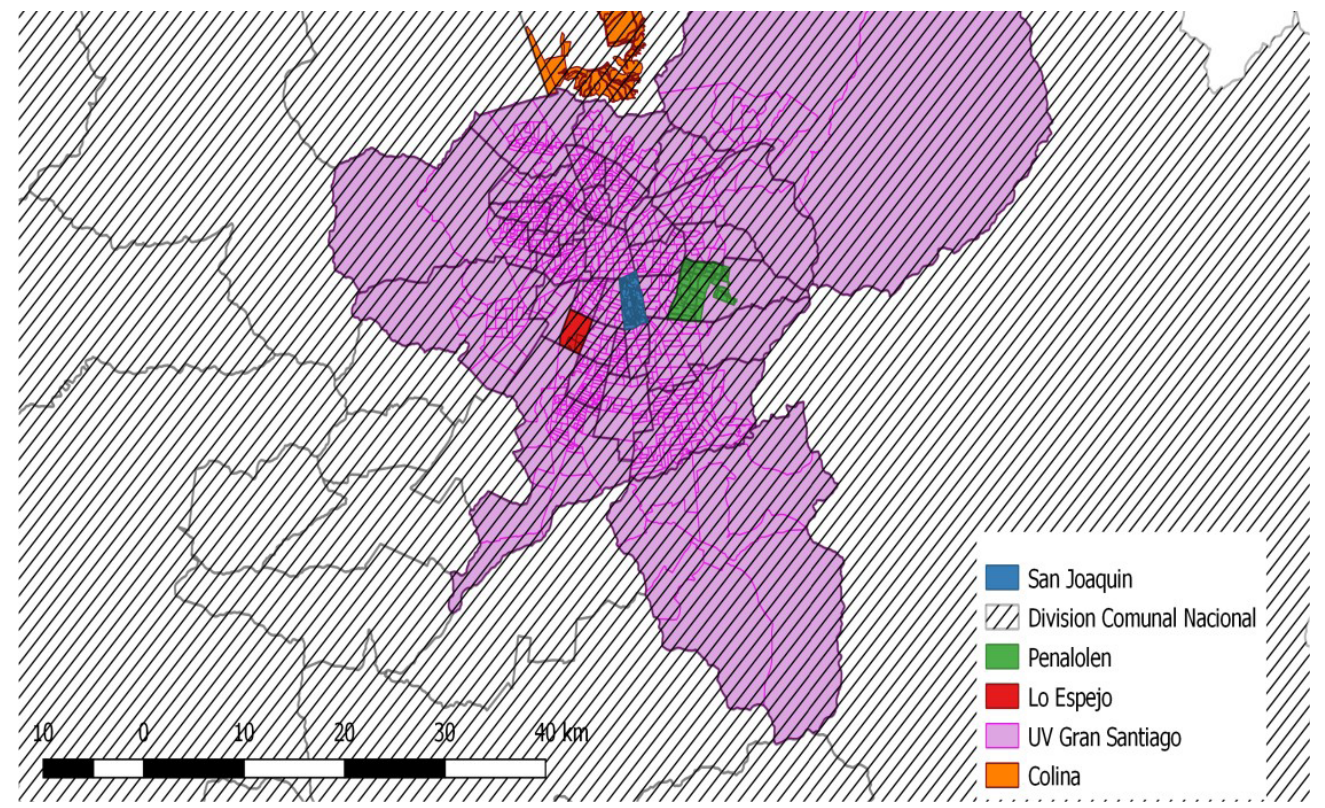

Fuente: Elaboración propia en Programa QGis utilizando datos proporcionados por IDE (2018).

Posterior a la selección de los barrios, se realizó un trabajo de revisión de prensa en línea, con el fin de analizar los significados mediáticos asociados a los barrios. En la sección de noticias de Google, se usaron palabras clave que refirieran directamente a alguno de los cuatro barrios seleccionados, y se analizaron los veinte primeros titulares referentes a los barrios -aunque no contuvieran el nombre del barrio en el titular- con el fin de categorizar los significados asociados.

La tercera etapa consistió en la inserción del equipo de investigación en cada uno de los barrios seleccionados, lo que se realizó en parejas y se operacionalizó mediante la toma de notas de campo, georreferenciación y la posterior discusión de los elementos observados en cada barrio, al modo de una técnica etnográfica que se acompañó de la elaboración de relatos auto-etnográficos en cada lugar. Así, se realizó una visita previa a cada barrio de una duración aproximada de dos horas, con el fin de sistematizar la labor de reconocimiento y documentación, la cual se presenta en fragmentos seleccionados en función de su pertinencia para el análisis de la mirada externa a los barrios.

\section{Selección de participantes}

La cuarta etapa del estudio está basada en una muestra de participantes jóvenes, que fueron los/as encargados de dar voz a sus propios territorios mediante el relato de sus experiencias subjetivas, dadas por el criterio de haber vivido la mayor parte de sus vidas en alguno de los cuatro barrios seleccionados. La inclusión de participantes jóvenes fue motivada fundamentalmente porque se trata de un grupo especialmente susceptible de procesos de exclusión social, debido al desigualdad acceso a oportunidades educativas o laborales (CEPAL, 2018; Jurado de los Santos, Olmos Rueda \& Pérez Romero, 2015; Krauspkoff, 2011; Saravi \& Makowki, 2011; Gallart, 2001). 
La muestra final contó con nueve jóvenes, cuatro mujeres y cinco hombres, de entre 20 y 27 años, con edad promedio de 24,22 años, incluyendo al menos un hombre y una mujer por barrio, con sólo un joven que no completó su participación. El Cuadro $N^{\circ} 2$ presenta un resumen de los y las participantes, considerando barrio de residencia actual y barrio de pertenencia, es decir, aquel donde habían vivido la mayor parte de sus vidas.

Cuadro $\mathrm{N}^{\circ} 2$

Resumen de jóvenes participantes en la investigación

\begin{tabular}{|l|c|c|c|c|}
\hline Pseudónimo & Edad & Barrio Pertenencia & Barrio actual & Con quién vive \\
\hline Andrea & 20 & Lo Hermida & Macul & Papá y señora \\
\hline Ester & 23 & Los Robles & Los Robles & Sola con hijo \\
\hline Farid & 24 & Los Robles & Los Robles & Padres y hermanos \\
\hline Bastián & 27 & Lo Hermida & Lo Hermida & Madre y hermanos \\
\hline Bernardo & 24 & J. M. Caro & J. M. Caro & Padres y hermanos \\
\hline Tomás & 27 & La Legua & San Miguel & Pareja y familia \\
\hline Darinka & 23 & La Legua & San Miguel & Pareja y familia \\
\hline Daniela & 27 & J. M. Caro & J. M. Caro & Abuela paterna \\
\hline Lautaro & 23 & J. M. Caro & J. M. Caro & Madre y hermano \\
\hline
\end{tabular}

Fuente: Elaboración propia

En términos de la producción de datos, con cada participante se realizaron tres encuentros individuales. En el primer encuentro se recogieron entrevistas biográficas (Autor/a, 2001). En el segundo encuentro, se realizaron entrevistas caminando por el barrio (Evans \& Jones, 2011), donde se visitaron los lugares considerados significativos por los/as jóvenes (tanto positiva como negativamente), y una cartografía participativa, donde se le pidió a cada uno que dibujara en una cartografía impresa los límites de lo que ellos/as consideraban su barrio. En el tercer encuentro se realizó un sombreo (Jirón, 2011), que fue audiograbado y videograbado, donde se acompañó a los/as jóvenes en sus trayectos urbanos cotidianos durante un día de movilidad por la ciudad. Al final de los tres encuentros individuales, se realizó una sesión de discusión grupal, donde se sometieron a reflexión colectiva los primeros resultados emergentes del análisis de datos, validando y transformando algunos de ellos a partir de la opinión de los/as participantes que asistieron a este cuarto encuentro.

En definitiva, el diseño metodológico se desarrolló a partir de un doble soporte, que consideró continuamente la relación entre experiencias subjetivas de los habitantes y caracterización de los barrios, así como entre metodologías basadas en la narración que fueron emplazadas también dentro de la experiencia de caminar y moverse por los espacios en cuestión. El diseño metodológico llevado a cabo permitió tensionar un análisis de la relación adentro-afuera, no silenciando el adjetivo de la exclusión puesto desde afuera, sino integrando este nivel a una comprensión desde el adentro que permitiera la emergencia de resultados novedosos respecto de la definición de barrios excluidos.

Con todo, las limitaciones del presente estudio se consignan principalmente en torno a su carácter exploratorio, con lo cual se sugiere continuar investigando las líneas de análisis presentadas, en proyectos que involucren metodologías a mayor escala. Asimismo, la comparabilidad entre los cuatro barrios estuvo dada por los criterios muestrales presentados, pero es posible 
pensar que el barrio de Los Robles constituye un tipo urbano diferente de los otros tres en materia de segregación urbana y conformación sociopolítica del territorio, con lo cual sería interesante en el futuro conducir una investigación que tensionara aún más estas variables para explorar sus efectos directos en las subjetividades del adentro de los barrios. Por último, es importante señalar que fue la diversidad de técnicas de producción de datos la que impidió una mayor amplitud muestral, lo que se consigna también como una limitación del presente estudio.

\section{Resultados}

\section{Etapa 1. El "afuera" de los barrios excluidos}

Tanto en la literatura como en las intervenciones públicas se ha definido barrio crítico, vulnerable o emblemático, como aquel territorio que ha desarrollado un cierto número de problemáticas socio-urbanas ligadas a la violencia y criminalidad de algunos grupos, que encuentran en estos barrios un cierto margen para operar sistemáticamente (e.g. Reyes, Arensburg \& Poó, 2016; Ruiz, 2009; Lunecke \& Ruiz, 2007). Sin embargo, recordando la advertencia que hace Wacquant (2007) de no olvidar el carácter histórico en los procesos de dualización de la ciudad, es importante señalar que las políticas habitacionales del siglo XX en Santiago contribuyeron a producir estos territorios que hoy se conocen como críticos, marginales o excluidos. Según Hidalgo (2002, 2004), este enfoque en materia de políticas de vivienda trajo consigo los inicios de la tendencia a segmentar los sectores populares de la población fuera de la cuadrícula clásica de la ciudad y hacia las periferias del sur.

A partir del año 2001, el Estado de Chile comenzó a intervenir territorios que denominó críticos, agrupando diez barrios en todo Chile para la implementación de la primera intervención urbana denominada Programa Barrio Seguro. Esta política pública se focalizó en lugares caracterizados por: i) tráfico y consumo de drogas; ii) prostitución; iii) ingesta de alcohol en vías públicas; iv) violencia interpersonal; y v) delitos de mayor connotación social (Manzano, 2009). A modo de crítica a esta estrategia, Ruiz (2009) nota que en estas políticas públicas se invisibiliza el capital social del barrio al focalizarse en sus problemáticas. En tanto, otros investigadores han planteado que estos barrios mayoritariamente han tenido una historia política vinculada a la resistencia de la dictadura y a la lucha obrera de los setenta (e.g. Álvarez, 2014; Garcés, 2013; Ganter, 2010; Garcés \& Leiva, 2005; Salman, 1994), con lo cual el desarrollo actual de sus problemáticas se encontraría también ligado con el lugar sociopolítico que habrían ocupado en el pasado. Todo lo anterior podría haber contribuido a generar lo que hoy se concibe como una cultura 'al margen', temerosa de los extraños a la vez que facilitadora para la instalación de bandas de narcotráfico (Lunecke \& Ruiz, 2007).

Por otro lado, no sólo las políticas públicas han definido 'el afuera' de los barrios seleccionados, sino que también existen procesos mediáticos en esta construcción de significados del barrio desde la mirada externa, muchas veces desde el estigma. Sobre la base del análisis de prensa, que se resume en el Cuadro $\mathrm{N}^{\circ} 3$, se encontró una evidente predominancia de referencias a violencia y delincuencia, frecuentemente ligadas con problemas de narcotráfico. Además, se pudo observar su evidente presencia en referencia a La Legua, más que a los otros tres barrios, de noticias principalmente asociadas a la intervención estatal o policial en el sector. Esto fue 
considerablemente menos frecuente en los otros tres barrios, que tuvieron en cambio predominancia de una mirada focalizada en los eventos delictivos o criminales, lo que es concordante con la sobreintervención que se ha documentado en La Legua (e.g. Reyes, Arensburg \& Poó, 2016; Manzano, 2009, Lunecke, Munizaga \& Ruiz, 2009). Por último, llamó la atención que en el barrio de Los Robles sólo se encontraron un total de cinco noticias, lo que confirma su menor presencia mediática en comparación con los otros tres barrios.

\section{Cuadro $\mathrm{N}^{\circ} 3$}

Resumen de resultados de Búsqueda en Google Noticias con palabras claves

\begin{tabular}{|l|c|c|c|c|c|c|}
\hline Categorías & La Legua & J. M. Caro & $\begin{array}{c}\text { Los } \\
\text { Robles }\end{array}$ & $\begin{array}{c}\text { Lo } \\
\text { Hermida }\end{array}$ & Total & Porcentaje \\
\hline Organización Social & 2 & 0 & 0 & 0 & 2 & 3,08 \\
\hline Violencia y/o Narcotráfico & 6 & 5 & 5 & 7 & 23 & 35,38 \\
\hline Historia o Patrimonio del barrio & 0 & 3 & 0 & 3 & 6 & 9,23 \\
\hline Desastres naturales & 2 & 1 & 0 & 0 & 3 & 4,62 \\
\hline Intervención estatal o policial & 9 & 3 & 0 & 0 & 12 & 18,46 \\
\hline Otros $^{6}$ & 1 & 8 & 0 & 10 & 19 & 29,23 \\
\hline Total & 20 & 20 & 5 & 20 & 65 & 100,00 \\
\hline
\end{tabular}

Fuente: Elaboración propia. Resultados extraídos de búsqueda en Google.cl de palabras claves "población+la+legua+san+Joaquín", "población+josé+maría+caro+lo+espejo", "población+los+robles+colina", "población+los+robles+colina+chile", "barrio+los+robles+colina+Santiago", "población+lo+hermida+Peñalolén", el 10/12/2018 en Google Noticias.

Figura $\mathrm{N}^{\circ} 2$

Caracterización y selección de notas de campo

José María Caro

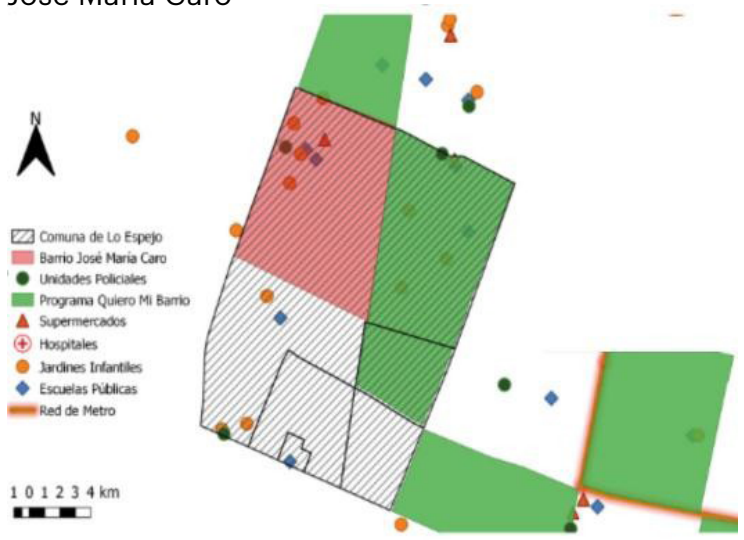

“En el primer semáforo, le preguntamos a un señor sobre dónde estaba la población José María Caro y cuáles eran sus límites. Señaló, algo difusamente: "todo esto es la Caro"".

"Lo primero que nos llamó la atención fue una estructura barrial que parecía especialmente rectangular, organizada en función de ejes urbanos más amplios por donde pasaba la locomoción colectiva, y por pequeños pasajes paralelos por donde apenas cabía el ancho de un automóvil. Suelos de tierra contrastando con calles principales pavimentadas $[\ldots]^{\prime \prime}$.

En la categoria "otros" se incluyeron noticias referentes, en la mayoría de los casos, a personajes o historias novedosas que no necesariamente se vinculaban con el barrio como unidad espacial y social. 


\section{Lo Hermida}

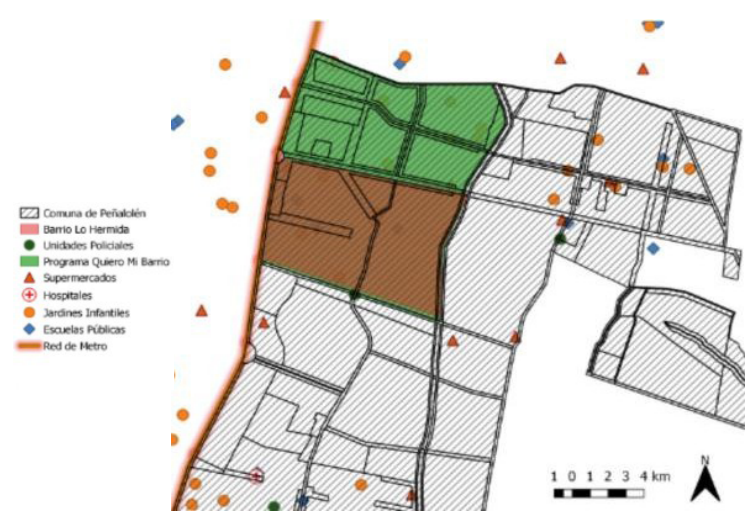

La Legua

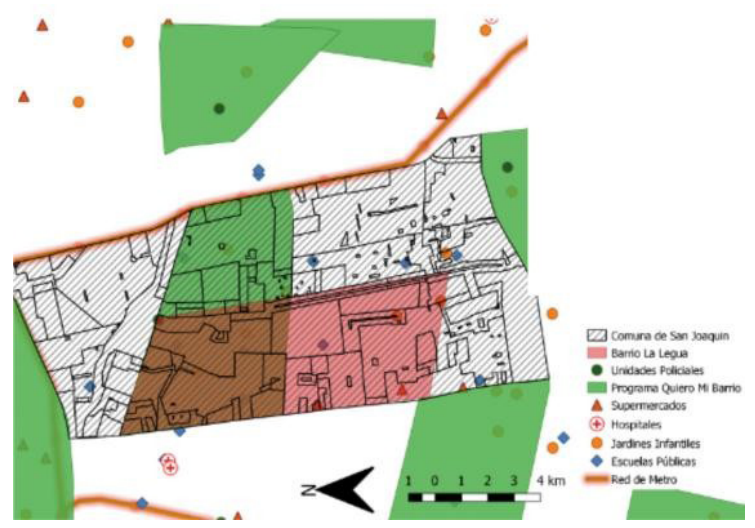

Los Robles

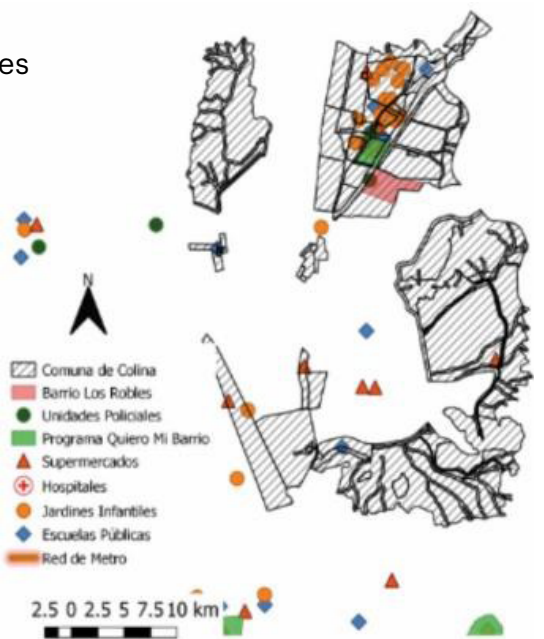

"Calles pequeñas donde apenas cabía un automóvil, y donde había que esperar que pasaran los camiones que venían en sentido contrario y que se detenían a conversar con los vecinos. Luego, sorprendernos con la feria, al pie de la calle, que tampoco dejaba pasar autos y daba cuenta de que la escala urbana en este lugar era peatonal".

"Fue llamativo notar que el paisaje café tierra de Lo Hermida se transformaba pronto en verde bosque y vegetación al salir de Lo Hermida. [...] En Lo Hermida, resuena la vecindad, las personas caminando y riendo en la calle, la feria, la cordillera y el color café".

"Seguimos caminando hacia el poniente por Canning, y nos encontramos con el clásico paisaje que aparece en fotos sobre la Legua Emergencia, de pasajes donde cuelgan por la mitad los cables que suelen tener papeles de colores colgando, $u$ otros artefactos. Desde dentro de los pasajes, algunas personas mirando nuestro paseo".

"Un poco más abajo nos encontramos con dos conocidos [...]. Y aquel hombre de pelo negro crespo y largo señala "ah, ustedes vienen a hacer turismo, mira qué bien", en tono de evidente reproche, agregando que las cosas habían estado violentas en el sector los últimos días".

“Un barrio tan lejos de la ciudad y pasando por peajes de más de $\$ 3000$ propios de las carreteras interurbanas de alta velocidad en Santiago".

"Calles marcadas por garras futboleras, o la presencia de una feria que daba la vuelta a la calle".

"Tratamos ir a registrar lo que los mismos habitantes de Los Robles sugerían eran sus límites [...] Unos caballeros que sonrientes nos contestaron, agregando una comparación de nuestra pregunta con la experiencia del Censo del día anterior".

Fuente: Elaboración propia en Programa QGis utilizando datos proporcionados por IDE (2018) y Centro de Inteligencia Territorial (2016). 
Por último, para avanzar en la caracterización de los cuatro barrios, se presenta la Figura 2, que compara un mapa de caracterización socio-urbana para cada barrio, junto a la presentación de algunas notas de campo sistematizadas en la inserción de duplas de trabajo en cada barrio, lo cual fue utilizado como parte del material de análisis del 'afuera'. De acuerdo con la labor de georreferenciación, es posible percibir que todos ellos se encuentran desprovistos de muchos servicios sociales, educacionales, comerciales y de transporte. Esto contrasta con su entorno en la ciudad, que muestra una mayor presencia de estos servicios, ilustrando el carácter aislado de estos barrios respecto del territorio urbano contiguo.

Por su parte, las notas de campo permiten dar cuenta de una sensación de aislamiento que es percibida por los/as investigadores, notando el contraste entre el adentro de los barrios y el afuera, marcado por la falta de zonas verdes y la poca conectividad, además de paisajes de callejones cerrados, y de una cultura barrial a escala peatonal que permite micro-interacciones fluidas entre vecinos, en espacios como la calle o la feria, a la vez que la mirada hacia los/as investigadores/as como ajenos al lugar o "turistas". En tanto, resulta llamativo que únicamente dos noticias sobre La Legua hacen referencia a la organización social o contestación.

En definitiva, la mirada desde fuera hace colar en sus significados elementos que pueden considerarse componentes claves de la exclusión socioespacial, al mostrar el barrio como lejano (Notas de Campo Auto-Etnografía, Los Robles), distinto respecto al resto de la ciudad (Notas de Campo Auto-Etnografía, Lo Hermida), y violento o extravagante (Titulares de Noticias centrados en violencia o crónicas). En efecto, no sólo se trata de barrios que hoy en día concentran problemáticas sociales como el narcotráfico o la violencia en espacios públicos (Ruiz Flores, 2012; Manzano, 2009), sino que presentan distinto grado de aislamiento socio-urbano en la ciudad, además de fuertes procesos de estigma y discriminación que dificultan los proyectos de movilidad urbana de sus habitantes (Rodríguez, 2016). La mirada desde fuera de los cuatro barrios seleccionados se caracteriza, de acuerdo con lo revisado, por la predominancia de conceptos como el aislamiento, la violencia y criminalidad presente en estos territorios, así como la fuerte presencia de la intervención social y policial.

\section{Etapa 2. El "adentro" de los barrios excluidos Tensiones entre el adentro y el afuera en materia de segregación espacial}

Algunos barrios se encuentran segregados debido a la organización morfológica del espacio, como es el caso de La Legua, barrio que, si bien tiene una localización pericentral dentro de la ciudad de Santiago, se comporta como si fuera una población periférica marcada por la segregación social, debido a sus características morfológicas (Lin Muñoz, 2012). Esto pues, a pesar de estar ubicado cerca de grandes avenidas (Santa Rosa, Carlos Valdovinos, Vicuña Mackenna), el barrio se encuentra encajonado por paños industriales que disminuyen su conectividad al resto de la ciudad (Salas, Rodríguez \& Rodríguez, 2009), similar a la morfología propia de una micro-ciudad aislada (Instituto Nacional de Derechos Humanos, 2015; Timo Jackel, 2009).

El caso de la población José María Caro es similar, ya que sus habitantes aluden a distintos factores morfológicos que restan conectividad al barrio con el resto de la ciudad. Como dice Daniela (27): 
"Yo igual, cuando viví en Ñuñoa andaba pa' todos lados en bicicleta, y acá tengo muchos problemas pa' las salidas: me corta el tren, me corta la carretera, entonces es como... O sino tengo que pasar por espacios más peligrosos... Entonces es difícil recorrer como en

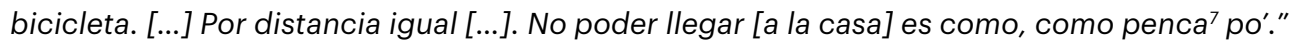
(Daniela, José María Caro, E2)

Por otra parte, el análisis de los datos recogidos permitió comprender que los barrios son experimentados subjetivamente más allá de la definición de sus límites geopolíticos oficiales, incorporando en su representación mental los procesos de movilidad urbana cotidiana que desarrollan los/as jóvenes. De hecho, en las nueve cartografías participativas realizadas, los/as jóvenes dan cuenta de un reconocimiento de los límites administrativos del barrio, a la vez que agregan algunas distinciones en los mapas, incluyendo por ejemplo espacios fuera de los límites administrativos, como muestra la Figura $\mathrm{N}^{\circ} 3$, de acuerdo con sus propias experiencias del territorio.

Figura $\mathrm{N}^{\circ} 3$

Cartografía participativa con Farid, 24 años, Los Robles (Colina)

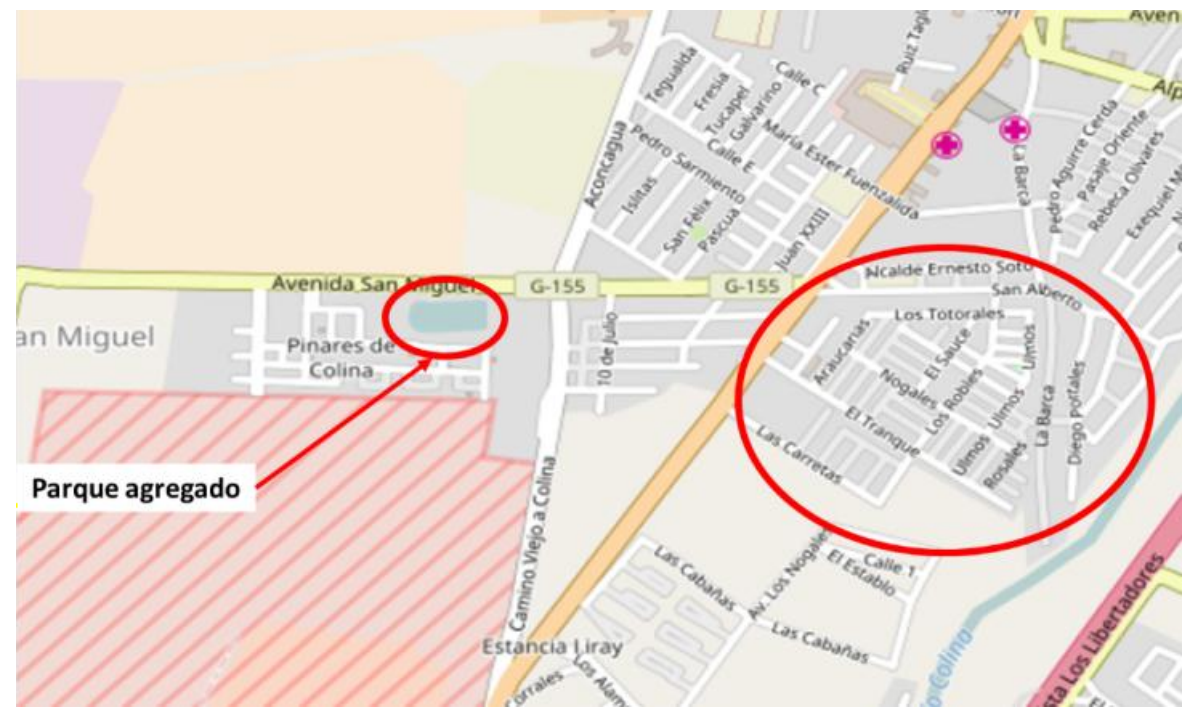

Fuente: Elaboración propia en Programa Paint

Así, como primera aproximación a la pregunta por el adentro y el afuera de la exclusión socioespacial, es interesante notar las tensiones que se producen entre la definición externa de los territorios, dirigidas por las políticas urbanas de una ciudad y por la historia geopolítica de los espacios, y las formas subjetivas de definir el espacio por parte de sus habitantes, tensionando conceptos claves como segregación y límite territorial. 


\section{¿Barrio crítico o "barrio-hogar"?}

Como se revisó anteriormente, los denominados barrios críticos presentan muchas problemáticas estructurales, como la violencia urbana, la delincuencia y/o el narcotráfico, que han sido profusamente abordadas por la literatura especializada. Sin embargo, esto contrasta con una percepción bastante común que tienen los y las jóvenes de sentirse seguros/as en sus barrios. Si bien todos/as registran algunas de las problemáticas asociadas a la violencia urbana, son claros/ as en señalar que estos elementos se tensionan con elementos positivos del barrio, como la organización social y la relación entre vecinos. Las experiencias positivas parecen estar, en su mayoría, dadas por un sentimiento de familiaridad expresado por los/as jóvenes, que han vivido la mayor parte de sus vidas en estos barrios. Lo que es interesante aquí es notar que esta familiaridad conlleva sentirse seguros/as, con un sentido de lo común dentro del barrio, desarrollando sentimientos de pertenencia y amistad entre vecinos, incluso frente a situaciones de violencia urbana que pueden atentar justamente contra esa seguridad. En palabras de Darinka (23):

"Quizás claro, yo veía gente fumando en la plaza po', allá en La Legua Vieja, pero los conocía po'. [...] Pero los conocía po', me saludaban, "buena" y no sé qué. Claro, eran pasteros ${ }^{8}$ o angustiados, pero eran mis pasteros po', o sea como los que yo conocía".

(Darinka, La Legua, E1)

Este primer elemento llama particularmente la atención, considerando que recientes estudios sobre criminalidad y violencia en barrios de Santiago han mostrado que existe una correlación inversa entre nivel socioeconómico de un barrio y frecuencia de situaciones de violencia e intimidación dentro del mismo (Tocornal, Tapia \& Carvajal, 2014). El estudio citado concluye que la presencia de lazos vecinales y cohesión social dentro del barrio no parece tener efectos en la percepción de su peligrosidad (Tocornal, et. al., 2014), con lo cual los relatos de seguridad y familiaridad que desarrollan los/as participantes de la presente investigación abren nuevas aristas respecto de cómo perciben y, no menos relevante, cómo quieren comunicar a otros -en este caso, los/as investigadores/as- la relación que tienen con sus barrios.

En efecto, los/as jóvenes señalan conocer los códigos sociales y no atemorizarse frente a situaciones que, desde fuera, podrían parecer problemáticas, lo que resulta coherente con investigaciones que señalan que uno de los elementos claves del apego al lugar dice relación con el sentimiento de continuidad e identidad asociado a los lugares (e.g. Droseltis \& Vignoles, 2010; Scannel \& Gifford, 2010; Manzo, Kleit \& Couch, 2008; Twigger-Ross \& Uzzel, 1996; Valera \& Pol, 1994). De hecho, la literatura internacional en esta materia, ha mostrado largamente que los seres humanos necesitan vincularse afectivamente con los espacios que habitan, estableciendo relaciones afectivas, identificatorias y de apego con sus entornos residenciales (e.g. Vidal, Berroeta, Di Masso, Valera \& Peró, 2013; Scannel \& Gifford, 2010; Valera \& Guardia, 2002; Valera \& Pol, 1994; Lewicka, 2011; Low, 1992; Tuan, 1991), incluso en contextos urbanos desfavorecidos o de fuerte estigmatización territorial (Kirkness, 2014; Jorgensen, 2010; Manzo, Kleit \& Couch, 2008).

"Pastero/a" se refiere a persona que consume pasta base, droga altamente expandida desde fines del siglo XX en sectores marginales de la ciudad latinoamericana 
Por otro lado, el sentimiento de familiaridad también está dado, según lo que refieren los/as participantes, por una valoración de la vida barrial, la sensación de ser conocido/a y conocer a los demás, y tener una vida social activa dentro del barrio, lo que algunas investigaciones han caracterizado como un fuerte lazo social presente en estos barrios (Manzano, 2009; Flock, 2005). Por ejemplo, es interesante detenerse en el caso de Daniela (27) quien señala sentirse segura en su barrio desde siempre, justamente por su grado de conocimiento, mientras que Tomás señala la importancia de la vida de barrio que conoció en La Legua:

"Caminar a mi casa no [me da] tanto [miedo] porque como que todos te conocen. Entonces es como que 'estás encargada"'.

(Daniela, José María Caro, E3)

“Vivir en barrios, por ejemplo, en poblaciones, te da que desde chico ves que existe la sociabilidad en las calles, ¿cachay? En las vecinas que se paran a conversar, en los cabros que se juntan, ¿cachay? Y es una actitud que nosotros vamos adquiriendo, ¿cachay? Desde siempre. El compartir".

(Tomás, La Legua, E1)

No se trata aquí de que los/as habitantes de un determinado barrio no registren las problemáticas asociadas con el mismo ni desarrollen estrategias conductuales de cuidado y protección para evitar algunos peligros, lo que fue también observado en el trabajo de campo. Más bien, se trata de que continuamente este registro de las problemáticas se confronta con la percepción de elementos positivos, no sólo del barrio sino del estar dentro del barrio. Esto parece traducirse, de manera general, en un sentimiento de familiaridad, que conlleva el sentirse protegidos/as por los/ as vecinos y sentirse en casa. Un sentimiento de interioridad social, dado por el hecho de pertenecer a un entramado social, tener un rol social definido ahí dentro, ser parte de y ser reconocido por los otros que viven ahí, como miembro de una comunidad (Rowles, 1983).

En definitiva, más allá de ser barrios excluidos, estos son sus barrios, y de esta forma representan una dimensión subjetiva de su identidad, de sus relaciones, de su propia historia, haciéndose imposible un registro desanclado de sus experiencias en el lugar. Es decir, ser de uno de esos barrios parece más relevante que estar ahí, con lo cual la experiencia subjetiva de vínculo con el barrio parece superar las problemáticas de exclusión barrial, como las balaceras, el narcotráfico, la intervención policial o la segregación.

\section{Desde las problemáticas percibidas hacia la exclusión comprendida}

A pesar de los sentimientos de familiaridad, seguridad y vínculo mayoritariamente positivo en los barrios donde han vivido la mayor parte de sus vidas, los/as jóvenes registran algunas problemáticas ligadas principalmente con sentir la exclusión social, por haber vivido o vivir en un barrio excluido. Algunos/as participantes relatan, desde su experiencia subjetiva, eventos donde se han sentido discriminados/as por vestir o hablar de acuerdo con lo aprendido en estos barrios. Por ejemplo, Ester (23) señala que:

"es muy complejo cuando tus habilidades lingüísticas no han sido las apropiadas [...]. Es super limitante, super limitante, sentirte inferior porque simplemente él [persona de fuera 
del barrio] está hablando de una forma y tú no entiendes o no puedes dar una respuesta apropiada [...]".

(Ester, Los Robles, E4)

Del mismo modo, Bastián analiza que la inserción laboral muchas veces implica abandonar ciertas formas de ser que son propias la población, por ejemplo, la manera de vestir, aun cuando tiene la sensación de que por más que se vista formal siempre será percibido como un "flaite" ${ }^{9}$.

"Yo soy así po", y espero poder vestirme así siempre. Y si algún día me gusta usar terno, ¡voy a usar terno po'! [...] ¡No, no me gusta el terno! ¡Un flaite con terno se ve más flaite! [¿Por qué?] iPorque no dejai' de ser cuma ${ }^{10}$ porque andes con terno po'! No pareces gerente, pareces Junior".

(Bastián, Lo Hermida, E3)

En efecto, estos/as jóvenes parecen dar cuenta de la experiencia de llevar en el cuerpo, en el modo de hablar o de vestir, una marca que limita las interacciones sociales que enfrentan fuera de estos barrios, y que pueden resultar más o menos difíciles considerando esta marca, recordando la exclusión social basada en estigma como un tipo de exclusión frecuente, justificada y compartida por el sistema hegemónico, por pertenecer a un grupo estigmatizado (Major \& Eccleston, 2004).

Algunos/as jóvenes desarrollan relatos más críticos de esta situación, planteando que no son ellos/as quienes deberían cambiar su modo de vestir o hablar, sino que este debiese ser un proceso de mutua adecuación entre personas distintas, considerando que "somos todos lo mismo, del mismo nivel" (Farid, 24 años, Los Robles, E4). Esto resultó particularmente llamativo en el cuarto encuentro grupal, donde la posibilidad de instalar una conversación colectiva sobre estos temas permitió a los/as jóvenes elaborar un discurso crítico de estas experiencias individuales de interacción estigmática.

Este discurso crítico de la exclusión social que se daría en estos territorios es expresado por Tomás (27), quien enfatiza que habría una voluntad política y económica de ofrecer alternativas educacionales en sus barrios, que estén al servicio de la jerarquía de clases. En sus palabras:

"La mayor parte de los colegios que nosotros tenemos a nuestro alrededor, son colegios técnicos, que eso significa que tú tienes que estudiar algo para poder en definitiva trabajar como obrero. [...] Es como una reproducción de obreros lo que se nos está entregando. A diferencia de otros lugares [con más dinero], si nos damos cuenta, [donde] tampoco son muchos los colegios técnicos que existen".

(Tomás, La Legua, E1)

"Flaite" es la denominación en Chile para persona de nivel socioeconómico bajo. Frecuentemente puede encontrarse vinculado con actividades delictuales y con una actitud displicente, considerándose un concepto de carácter peyorativo

10 Sinónimo de "flaite", que no tiene necesariamente la connotación delictual, aunque sí peyorativa y referente a alguien de clase socioeconómica baja. 
En este sentido, más allá de la percepción que los/as participantes registran de las problemáticas socioespaciales de sus barrios, las narrativas parecen girar de manera insistente en torno a las formas que tienen de comprender estos elementos como verdaderos procesos de exclusión social que, más allá de su resultado visible, se encuentran en articulación compleja con el sistema social dominante. Así, la exclusión de los cuatro barrios analizados parece reportarse en los/as participantes en experiencias de distancia o aislamiento subjetivo de los códigos sociales hegemónicos, es decir, a través de las experiencias de hablar o verse diferentes. Sin embargo, estas experiencias subjetivas son comprendidas dentro de un análisis más complejo de la exclusión social como fenómeno dialéctico, y los/as participantes dan cuenta de una mirada crítica que cuestiona la noción de déficit o inadecuación, planteando que vivir en barrios excluidos conlleva procesos de estigma y desigualdad que son estructurales a la sociedad (Major \& Eccleston, 2004).

En definitiva, respecto de los análisis de contenido llevado a cabo con los relatos de los y las jóvenes entrevistados/as, existen dos elementos que parecen ejercer una tensión significativa en cuanto a los contenidos emergentes desde el afuera. No sólo los/as jóvenes parecen vincularse con barrios que cuestionan las definiciones sociopolíticas del afuera, sino que su experiencia subjetiva de sentirse excluidos/as parece sobreponerse a la cuestión de las problemáticas socio-urbanas, observando procesos de violencia simbólica en sus barrios y percibiendo su fuerza en las interacciones cotidianas.

\section{Conclusiones}

Los resultados de la presente investigación nos muestran que muchas veces la forma en que es entendido el barrio desde un punto de vista externo no coincide del todo con la percepción subjetiva de sus habitantes. Si bien los/as participantes registran las dimensiones problemáticas del barrio de diversa forma, entregan también matices, obligando a repensar el concepto de exclusión y resaltando la violencia simbólica que opera justamente desde la mirada externa. Es decir, las líneas analíticas que organizan los resultados permiten comprender que las formas de hablar del propio barrio, desde la perspectiva émica o desde dentro, tensionan las características supuestamente problemáticas de estos lugares estigmatizados, y ponen en juego la pregunta del 'a quién' se le está hablando. Como se ha señalado, es interesante reconsiderar la escala barrial para comprender fenómenos vinculados con la exclusión social y el hacer ciudad, reconsiderando la importancia de la subjetividad y las experiencias cotidianas de quienes viven en los barrios que se estudian (Gallastegui-Vega, Rojas-Rubio \& Pérez-Muñoz, 2018).

Por una parte, esto nos lleva a ampliar la definición tradicional de barrio como "un territorio más pequeño y abarcable según la experiencia cotidiana" (Tocornal, et. al., 2014: 84), acercándonos más una concepción que tensione la unicidad estática de un territorio por medio de sus significados subjetivos. Así, comprendemos la noción de barrio a partir de procesos dialécticos, entre las percepciones subjetivas de quienes viven ahí, que adquieren un carácter performativo a la hora de concebir el barrio, y las definiciones externas de los barrios que buscan abstraer sus significados para delimitar una unidad territorial específica. Esto resulta particularmente relevante cuando pensamos en las características de los que consideraremos barrios excluidos dentro de una ciudad, así como también la definición de los barrios desde la política pública. 
Con todo, la presente investigación muestra que las percepciones subjetivas (o desde dentro) de los/as jóvenes de barrios excluidos dan cuenta de un reconocimiento de la desigualdad estructural y la segregación urbana que los/as aqueja, pero también de una visión muy crítica de esta situación y de los estigmas espaciales que se les imputa a sus barrios. En este sentido, el barrio excluido debe ser entendido como un barrio que sigue las lógicas de segregación mencionadas más arriba, a la vez que un escenario urbano que resiste a estas formas de hacer ciudad, planteándose como escenario de identificaciones, afectos, relaciones, sentimientos de familiaridad y seguridad, que cuestionan los discursos dominantes sobre lo indeseable, lo estigmatizado o lo marginal.

En definitiva, se hace necesario entonces volver la mirada hacia el concepto de exclusión social en términos más generales, puesto que hablar de excluidos/as e investigar la exclusión, supone una etiqueta desde fuera a una realidad considerada lejana y hasta cierto punto fuera de la ley (Wacquant, 2001, 2007), conteniendo con ello el riesgo de invisibilizar las dimensiones de cómo se vive el barrio por dentro, además de reproducir la lógica excluyente. Aún más, las políticas públicas en materia de segregación y exclusión social urbana pueden enriquecerse a partir de trabajos de investigación que exploren el carácter relacional y dinámico de los procesos que se dan en cada territorio de manera particular (Reyes, Arensburg \& Poó, 2016; Lunecke, Munizaga \& Ruiz, 2009; Flock, 2005), yendo más allá de nociones unilaterales de déficit. Aún más, es importante señalar que son los/as propios/as participantes quienes enfatizan la importancia de pensar esta dialéctica, lo cual hace suponer que el concepto de exclusión social permite dar voz y participación a las personas que viven estas problemáticas desde dentro.

Por último, ¿es aún pertinente hablar de barrios excluidos, como escenarios urbanos que concentran tantas problemáticas como riquezas psicosociales? El presente artículo concluye que el concepto de barrio excluido sigue siendo pertinente, en la medida en que resalta la dimensión dialéctica en la génesis del proceso de exclusión social; además, dejar de nombrar la exclusión social puede convertirse también en otra forma de invisibilización. Ahora bien, creemos que al nombrar el concepto de barrio excluido no puede dejar de recordarse su análisis desde dentro, considerando que, en medio de los procesos de exclusión social, son los sujetos quienes están cotidianamente tensionando las imposiciones del afuera y actualizando, con ello, las posibilidades de cambio social.

En definitiva, los seres humanos se relacionan con los lugares de una manera significada, afectiva, y performativa, así como los lugares en sí mismos contienen disposiciones materiales e históricas que los determinan. Es justamente en esta relación afuera-adentro que se producen intercambios significativos, ya que son los sujetos quienes tensionan y significan los procesos de exclusión social a través de sus experiencias cotidianas, cuestionando y adaptando las formas tradicionales de concebir el barrio y la ciudad.

\section{Bibliografía}

Agostini, C.; Brown, P. y Góngora, D. (2008). Distribución espacial de la pobreza en Chile. Estudios de Economía, 35(1): 79-110. doi: 10.4067/S071852862008000100005. 
Agostini, C.; Hojman, D.; Román, A. \& Valenzuela, L. (2016). Segregación residencial de ingresos en el Gran Santiago, 1992-2002: una estimación robusta. Revista Eure, 42 (127): 159 - 184. ISSN digital 0717-6236.

Álvarez, P. (2014). Legua Emergencia: una historia de dignidad y lucha. Ediciones Universidad Diego Portales, 1era Édición. Santiago, Chile.

Álvarez, A. M. \& Cavieres, H. (2016). El Castillo: territorios, sociedad y subjetividades de la espera. Revista Eure, 12 (125): 155 - 174.

Bauman, Z. (2007). Tiempos líquidos. Vivir en una época de incertidumbre. Tusquets Editores: Barcelona, España.

Brandt, N. (2012). Reducing poverty in Chile: Cash transfer and better jobs. OECD Economics Department Working Papers, No.951, OECD Publishing. doi: 10.1787/5k9bdt4pld6h-en

Centro de Inteligencia Territorial [CIT] (2016). Datos proporcionados en contexto de colaboración y formación en uso de Programas de Análisis Geoespaciales.

CEPAL (2018). Panorama social de América Latina. Documento informativo. Bárcena, A.; Cimoli, M.; García-Buchaca, R.; Abramo, L. \& Pérez, R. (Eds.). Rescatado el 30-01-2019 en URL: https:// repositorio.cepal.org/bitstream/handle/11362/44395/5/S1801084_es.pdf

Consejo Nacional de Desarrollo Urbano [CNDU] (2015). Propuestas para una política de suelo para la integración social urbana, Informe Final. Gobierno de Chile. Extraído de URL: http://cndu.gob. cl/wp-content/uploads/2015/05/Documento_Final_Propuesta-de- Poli\%CC\%81ticas_Suelo_para_ Integracio\%CC\%81n_Social_CNDU_Mayo_2015.pdf

Cornejo, M.; Besoain, C. y Mendoza, F. (2011). Desafíos en la generación de conocimiento en la investigación social cualitativa contemporánea. Forum: Qualitative Social Research, 12 (9).

De Mattos, C.; Fuentes, L. \& Link, F. (2014). Tendencias recientes del crecimiento metropolitano en Santiago de Chile: ¿Hacia una nueva geografía urbana? Revista INVI, 29 (91): 193- 219.

Denzin, N. K. (2001). The reflexive interview and a performative social science. Qualitative Research, I (I): 23-46.

Droseltis, O. \& Vignoles, V. L. (2010). Towards an integrative model of place identification : dimensionality and predictors of intrapersonal-level place preferences. Journal of Environmental Psychology, 30: 23-34. doi: 10.1016/j.jenvp.2009.05.006

Espinoza, V. (1998). Historia social de la acción colectiva urbana: los pobladores de Santiago, 1957-1987. Revista EURE, 24 (72). doi: 0.4067/S0250-71611998007200004

Evans, J. \& Jones, P. (2011). The walking interview: methodology, mobility and place. Applied Geography, 31: 849-858. doi: 10.1016/j.apgeog.2010.09.005. 
Flock, Wigbert (2005). Pobreza y autoorganización en Santiago de Chile. Un estudio etnográfico en el barrio José María Caro. Revista Mexicana de Sociología, 67(1): 1-30.

Fraile, L. (2009). Lessons from Latin America's neo-liberal experiment: an overview of labour and social policies since the 1980s. International Labour Review, 148(3): 215 - 233.

Fuentes, L. \& Link, F. (2014). Competitividad, mercados del trabajo y estructura socioterritorial en Bogotá, Lima y Santiago. Revista de Geografía Norte Grande, 59: 105 - 122.

Gallart, M. A. (2001). Poverty, youth and training: a study on four countries in Latin America. Compare, vol. 31 (1): 113-128. doi: 10.1080/0305792002003019 9.

Gallastegui-Vega, J.; Rojas-Rubio, I. \& Pérez-Muñoz, R. (2018). Enseñanza geográfica y desarrollo barrial. Una mirada desde la Geografía social crítica. Revista de Geografía Norte Grande, 70: 31 50 .

Ganter, R. (2010). Escenas de la vida urbana en la Legua Emergencia: narcocultura y ambivalencias identitarias. Tesis para optar al grado de Doctor. Pontificia Universidad Católica de Chile, Santiago de Chile.

Garcés, M. (2013). Tomando su sitio. El movimiento de pobladores de Santiago 1957 - 1970. Ediciones LOM. Santiago, Chile.

Garcés, M. \& Leiva, S. (2005). El golpe en La Legua. Los caminos de la historia y la memoria. Ediciones LOM. Santiago, Chile.

Giddens, A. (2009). Sociología. Alianza Editorial, Sexta Edición. Madrid, España.

Haraway, D. (1988). Situated knowledges: the science question in feminism and the privilege of partial perspective. Feminists Studies, 14 (3): 575 - 599. doi: 143.167.174.152

Hidalgo, R. (2002). Vivienda social y espacio urbano en Santiago de Chile. Una mirada retrospectiva a la acción del Estado en las primeras décadas del siglo XX. Revista EURE, 28(83). doi: 10.4067/ s0250-71612002008300006.

Hidalgo, R. (2004). La vivienda social en Santiago de Chile en la segunda mitad del siglo XX: actores relevantes y tendencias espaciales. En: Santiago en la Globalización: ¿una nueva ciudad? Ediciones SUR (Corporación de Estudios Sociales y Educación), Santiago de Chile.

Infraestructura de Datos Geoespaciales [IDE] (2018). Descarga de Capas. Ministerio de Bienes Nacionales. Rescatado el 03/2018 en URL: http://www.ide.cl/descarga/capas.html

Instituto Nacional de Derechos Humanos - INDH (2015). Estudio de caso. Violencias y derechos humanos en La Legua. Santiago de Chile. Rescatado el 20/06/2016 en URL: http://bibliotecadigital. indh.cl/bitstream/handle/123456789/857/Estudio.pdf?sequence=1 
INVI (2005). Glosario INVI del hábitat residencial. Sistematización teórica - conceptual en el marco de un Sistema de Información de Vivienda (SIV). Instituto de la Vivienda, Facultad de Arquitectura y Urbanismo. Universidad de Chile. Rescatado el 30/12/2016 en URL: http://repositorio.uchile.cl/ handle/2250/118206

Jirón, P. (2011). On becoming "la sombra/the shadow". En: M. Buscher, J. Urry \& K. Witchger (Eds.). Mobile methods. Ed. Routledge. Nueva York, EEUU.

Jorgensen, A. (2010). The sense of belonging in new urban zones of transition. Current Sociology, 58(1): 3-23. doi: 10.1177/0011392109348542

Jurado de los Santos, P.; Olmos Rueda, P. \& Pérez Romero, A. (2015). Los jóvenes en situación de vulnerabilidad y los programas formativos de transición al mundo del trabajo. Educar, 51 (1): 211-224. doi: 10.5565/rev/educar.648

Kirkness, P. (2014). The cites strike back: restive responses to territorial taint in the French banlieues. Environment and Planning A, 46: 1281-1296. doi: 10.1068/a45636

Krauskopf, D. (2011). Enfoques y dimensiones para el desarrollo de indicadores de juventud orientados a su inclusión social y calidad de vida. Última Década, 34: 51-70.

Kruijt, D. y Koonings, K. (2007). Actores armados y ciudades fragmentadas. Foreign Affairs (En Español), 7(2): 11-21.

Lewicka, M. (2011). Place attachment: how far have we come in the last 40 years? Journal of Environmental Psychology,31: 207-230. doi: 10.1016/j.jenvp.2010.10.001.

Lin Muñoz, T. (2012). Desarmar el laberinto. Violencia, estructura física e intervención en Legua Emergencia. Tesis presentada al Instituto de Estudios Urbanos y Territoriales de la Pontificia Universidad Católica de Chile para optar al título profesional de Arquitecto y grado académico de Magíster en Desarrollo Urbano. Santiago, Chile.

Link, F.; Valenzuela, F. \& Fuentes, L. (2015). Segregación, estructura y composición social del territorio metropolitano en Santiago de Chile. Complejidades metodológicas en el análisis de la diferenciación social en el espacio. Revista de Geografía Norte Grande, 62: 151 - 168.

Low, S. M. (1992). Symbolic ties that bind. In I. Altman, \& S. M. Low (Eds.). Place attachment (pp. 165-185). New York: Plenum Press.

Lunecke, A.; Munizaga, A. M. \& Ruiz, J. C. (2009). Violencia y delincuencia en barrios: sistematización de experiencias. Fundación Paz Ciudadana y Universidad Alberto Hurtado. Rescatado el 28/06/17 en URL: https://es.scribd.com/document/346766584/Violencia-y-Delincuencia-en-Barrios Lunecke A. y Ruíz J. C. (2007). Capital social y violencia: Análisis para la intervención en barrios urbanos Críticos. Ed. Universidad Alberto Hurtado. Santiago, Chile. 
Major, B. \& Eccleston, C. (2004). Stigma and social exclusion. En: D. Abrams; M. A. Hogg \& J.

M. Marques (Eds.). Social Psychology of Inclusion and Exclusion. New York: Psychology Press.

Manzano, L. (2009). Violencia en barrios críticos. Explicaciones teóricas y estrategias de intervención basadas en el papel de la comunidad. Centro de Estudios en Seguridad Ciudadana CESC. Universidad de Chile. Instituto de Estudios Públicos.

Manzo, L.; Kleit, R. \& Couch, D. (2008). "Mooving three times is like having your house on fire once": the experience of place and impeding displacement among public housing residents. Urban Studies, 45 (9): 1855-1878. doi: 10.1177/0042098008093381

Mingione, E. \& Oberti, M. (2003). The struggle against social exclusion at the local level. Diversity and convergence in European cities. European Journal of Spatial Development, 1: 1-23. http://www. nordregio.se/EJSD/-ISSN 1650-9544-Refereed Article

Mingione, E. (1997). The current crisis of intensive work regimes and the question of social exclusion in industrialized countries. Discussion Paper, FS I 97-105, Wissenschaftszentrum Berlin für Sozialforschung: 1-28.

Ministerio de Vivienda y Urbanismo [MINVU] (2014-2018). Zonas prioritarias 2014-2018. Extraído de: http://www.minvu.cl/opensite_20140214175813.aspx

Ortega, T. (2014). Criminalización y concentración de la pobreza urbana en barrios segregados. Síntomas de guetización en La Pintana, Santiago de Chile. Eure, 40(120): 241-263.

Parraguez, Leslie (2010). Reconstrucción de los movimientos sociales urbanos: aprendizajes a partir del caso de la Coordinadora de Pobladores José María Caro en Santiago de Chile. Infonavit: Universidad Autónoma del Estado de México (UAEM), Facultad de Ciencias Políticas y Sociales.

Patton, M. Q. (2002). Qualitative research \& evaluation methods. Thousand Oaks, C.A: Sage. California, EEUU.

Prevot-Schapira, M. F. (2005). De l'usage de la fragmentation urbaine en Amérique Latine (vue de Buenos Aires). Bulletin de l'Association de Géographes Français, vol. 82 n4 : 483 - 495.

Rasse, A. (2015). Juntos pero no revueltos. Procesos de integración social en fronteras residenciales entre hogares de distinto nivel socioeconómico. Revista Eure, 41 (122): 125 - 143.

Reyes, M. J.; Arensburg, S. \& Póo, X. (2016). Vidas cotidianas en emergencia. Territorios, habitantes y prácticas. Social-Ediciones. Facultad de Ciencias Sociales, U. de Chile. Santiago, Chile.

Reyes, M. J. (2016). Vidas cotidianas en emergencia como campo de la investigación social. En: M. J. Reyes, S. Arensburg \& X. Póo (Coord.). Vidas cotidianas en emergencia. Territorios, habitantes y prácticas. Social-Ediciones. Facultad de Ciencias Sociales, U. de Chile. Santiago, Chile. 
Rivera, A. (2012). Historia de la política habitacional en el área metropolitana de Santiago. Revista CIS, 16(16): 27-44.

Rodríguez, P. (2016). El debilitamiento de lo urbano en Santiago, Chile. Revista Eure, 42 (125): 61 79.

Rowles, G. D. (1983). Place and personal identity in old age: observations from Appalachia. Journal of Environmental Psychology, 3: 299 - 313.

Ruiz Flores, J. C. (2012). Violencias en la periferia de Santiago. La población José María Caro. Revista INVI, 26(74): 249-285.

Ruiz, J. C. (2009). Violencia y capital social en Santiago: Notas para entender los barrios vulnerados y los barrios críticos. En A. Lunecke, A. M. Munizaga, \& J. C. Ruiz (Eds.), Violencia y Delincuencia en Barrios: Sistematización de Experiencias (pp. 53-93). Santiago: Fundación Paz Ciudadana - Universidad Alberto Hurtado.

Sabatini, F.; Rasse, A.; Cáceres, G.; Robles, M. S.; \& Trebilcock, M. P. (2017). Promotores inmobiliarios, gentrificación y segregación residencial en Santiago de Chile. Revista Mexicana de Sociología, 79 (2): $229-260$.

Salas, X, Rodríguez, A y Rodríguez, P. (2009). Revitalización y reconversión de la Legua. En A. Lunecke, A.M. Munizaga y J.C. Ruiz (Eds). Violencia y delincuencia en barrios: sistematización de experiencias. Ed. Universidad Alberto Hurtado. Santiago, Chile.

Salman, T. (1994). Challenging the city, joining the city: the Chilean Pobladores between social movements and social integration. Bulletin of Latin American Research, 13 (1): 79 - 90. http://www. jstor.org/stable/3338702

Sandoval, J. (2013). Una perspectiva situada de la investigación cualitativa en ciencias sociales. Cinta Moebio, 46: 37-46.

Saravi, G. y Makowski, S. (2011). Social exclusion and subjectivity: Youth expressions in Latin America. The Journal of Latin American and Caribbean Anthropology, 16(2): 315-334. doi: 10.1111/j.19354940.2011.01160.x

Sassen, S. (2003). Globalization or denationalization? Review of International Political Economy, 10 (1): 1-22 [Editor's Note].

Scannell, L. \& Gifford, R. (2010). Defining place attachment: a tripartite organizing framework. Journal of Environmental Psychology, 30: 1 - 10. doi: 10.1016/j.jenvp.2009.09.006

Sisto, V. (2008). La investigación como una aventura de producción dialógica: la relación con el otro y los criterios de validación en la metodología cualitativa contemporánea. Psicoperspectivas, VII: 114-136. 
Subsecretaría Prevención del Delito [SPD] (2013). Compendio buenas prácticas en prevención del delito. Ministerio del Interior y Seguridad Pública. Extraído de: http://www.seguridadpublica.gov. cl/filesapp/Compendio\%2OBuenas\%2OPracticas\%20V F.pdf

Timo Jackel, F. (2009). Legua Emergencia: Un retrato de una pieza provisoria de ciudad. Revista 180, n²4, año 13: pp.46 - 49. Universidad Diego Portales.

Tocornal, X.; Tapia, R. \& Carvajal, Y. (2014). Delincuencia y violencia en entornos residenciales de Santiago de Chile. Revista de Geografía Norte Grande, 57: 83 - 101.

Tuan, Y. F. (1991). Language and the making of place: a narrative-descriptive approach. Annals of the Association of American Geographers, 81(4): 684-696.

Twigger-Ross, C. \& Uzzel, D. (1996). Place and identity processes. Journal of Environmental Psychology, 16: $205-220$.

Valera, S. \& Pol, E. (1994). El concepto de identidad social urbana: una aproximación entre la Psicología Social y la Psicología Ambiental. Anuario de Psicología, 64: 5-24.

Vidal, T.; Berroeta, H.; Di Masso, A.; Valera, S. \& Peró, M. (2013). Apego a lugar, identidad de lugar, sentido de comunidad y participación en un contexto de renovación urbana. Estudios de Psicología, 34 (3): 275-286. doi: 10.1174/021093913808295172.

Wacquant, L. (2001). Parias urbanos. Marginalidad en la ciudad a comienzos del milenio. Editorial Manantial. Buenos Aires, Argentina.

Wacquant, L. (2007). Los condenados de la ciudad. Gueto, periferias y Estado. Siglo XXI Editores, 1era Edición. Buenos Aires, Argentina.

Ziccardi, A. (2008). Pobreza y exclusión social en las ciudades del siglo XXI. En: Sader, E. (Ed.) y Ziccardi, A. (Comp.). Procesos de urbanización de la pobreza y nuevas formas de exclusión social. Los retos de las políticas sociales de las ciudades latinoamericanas del siglo XXI. Siglo del Hombre Editores, Clacso-Crop. Bogotá, Colombia. 
